\title{
Prognosis of breast cancer is associated with one-carbon metabolism related nutrients among Korean women
}

Yunhee Lee ${ }^{1}$, Sang-Ah Lee ${ }^{2}$, Ji-Yeob Choi ${ }^{1}$, Minkyo Song ${ }^{1}$, Hyuna Sung ${ }^{1}$, Sujee Jeon ${ }^{3}$, Sue K Park ${ }^{4}$, Keun-Young Yoo ${ }^{4}$, Dong-Young Noh ${ }^{5}$, Sei-Hyun Ahn ${ }^{6}$ and Daehee Kang ${ }^{4,7^{*}}$

\begin{abstract}
Background: The 5-year survival rate for breast cancer among Korean women has increased steadily; however, breast cancer remains the leading cause of cancer mortality among women. One-carbon metabolism, which requires an adequate supply of methyl group donors and $B$ vitamins, may affect the prognosis of breast cancer. This aim of this study was to investigate the associations of dietary intake of vitamin $B_{2}$, vitamin $B_{6}$ and folate before diagnosis on the prognosis of breast cancer.
\end{abstract}

Methods: We assessed the dietary intake using a food frequency questionnaire with 980 women who were newly diagnosed and histopathologically confirmed to have primary breast cancer from hospitals in Korea, and 141 disease progression events occurred. Cox's proportional hazard regression models were used to estimate the hazard ratio (HR) and 95\% confidence interval (95\% Cl) adjusting for age, education, recruitment sites, TNM stage, hormone status, nuclear grade and total calorie.

Results: There was no significant association between any one-carbon metabolism related nutrients (vitamin $B_{2}, B_{6}$ and folate) and the progression of breast cancer overall. However, one-carbon metabolism related nutrients were associated with disease progression in breast cancer patients stratified by subtypes. In ER + and/or PR + breast cancers, no association was observed; however, in ER-/PR- breast cancers, a high intake of vitamin $\mathrm{B}_{2}$ and folate statistically elevated the HR of breast cancer progression $(\mathrm{HR}=2.28 ; 95 \% \mathrm{Cl}, 1.20-4.35, \mathrm{HR}=1.84 ; 95 \% \mathrm{Cl}, 1.02-3.32$, respectively) compared to a low intake. This positive association between the ER/PR status and progression of the disease was profound when the nutrient intakes were categorized in a combined score $\left(P_{\text {interaction }}=0.018\right)$. In ER-/PR- breast cancers, high combined scores were associated with a significantly poor DFS compared to those belonging to the low score group ( $\mathrm{HR}=3.84 ; 95 \% \mathrm{Cl}$, 1.70-8.71).

Conclusions: In conclusion, our results suggest that one-carbon related nutrients have a role in the prognosis of breast cancer depending on the ER/PR status.

Keywords: Breast cancer prognosis, One-carbon metabolism, Vitamin $B_{2}$, Vitamin $B_{6}$, Folate

\footnotetext{
* Correspondence: dhkang@snu.ac.kr

${ }^{4}$ Department of Preventive Medicine, Seoul National University, Seoul, Republic of Korea

${ }^{7}$ Department of Preventive Medicine, Seoul National University College of Medicine, 103 Yongon (Daehangno), Jongno-gu, Seoul, Republic of Korea Full list of author information is available at the end of the article
} 


\section{Introduction}

Breast cancer is the second most common malignancy in Korea. The 5-year survival rate for breast cancer among Korean women has increased from $78.0 \%$ during 1993-1995 to $89.5 \%$ during 2003-2007. Despite such marked improvement, breast cancer remains the second leading cause of cancer mortality among women in Korea [1]. Analyzing prognostic factors associated with breast cancer survival and recurrence is important for early detection and chemotherapy.

Known prognostic indicators such as pathological criteria including tumor size, lymph-node status and hormone receptor status are pathologically used in clinical practice [2]. Although numerous studies have shown that disease-free survival after breast cancer treatment may be partially predicted by pathological factors [3,4], they are not yet predicted prognostic factors for each patient in clinical practice.

Epigenetic aberrations occur in tumor cells; especially, CpG-island hypermethylation and global genomic hypomethylation are common features of breast cancer cells [5]. A lack of methyl supply can induce DNA global hypomethylation as well as incomplete conversion of dUMP to dTMP leading to uracil misincorporation into DNA [6]. One-carbon metabolism is a network of interrelated biochemical reactions that include the transfer of one-carbon groups [7], which have two major functions: DNA methylation and DNA synthesis [8].

The principal element of one-carbon metabolism is folate, since the one-carbon transfer reactions involve interconversion between several forms of this nutrient. Other important nutrients in one-carbon metabolism include vitamins $B_{2}, B_{6}$ and $B_{12}$, which act as essential cofactors for one or more enzymes that catalyze one-carbon transfer reactions. Vitamin $B_{2}$ is a cofactor for methylenetetrahydrofolate reductase, the critical folate-dependent enzyme. Vitamin $\mathrm{B}_{6}$ has a role in the conversion of tetrahydrofolate to 5,10 -methylenetetrahydrofolte, which is required for the synthesis of thymidylate and a precursor for purine synthesis $[9,10]$.

Previous studies have suggested that a high status of one-carbon metabolism factors has reduced the risk of several cancers, including colorectal, pancreatic, esophageal, renal cell, and breast cancer [11-15]. In studies related to breast cancer risk, folate has been investigated many times. Although a number of cohort and casecontrol studies have suggested a protective effect for a high folate status on breast cancer risk, these results are far from conclusive. And other B vitamins did not showed any associations with breast cancer risk [15]. For studies on one-carbon metabolism related nutrients and breast cancer survival, a few investigated the association between folate intake and breast cancer survival with inconsistent results. In a Swedish mammography study, high folate intake before breast cancer diagnosis improved the prognosis of the breast cancer and overall survival [16]. However, in the Long Island Breast Cancer Study Projects and Nurses' Health study, the association between vitamin $B_{2}, B_{6}$ and folate and breast cancer prognosis had null results $[17,18]$.

One-carbon metabolism, which requires an adequate supply of methyl group donors and B vitamins, may modify the methylation profile of the genome, thus influencing breast cancer prognosis. The aim of this study was to investigate the associations of dietary intake of vitamin $B_{2}$, vitamin $B_{6}$ and folate before diagnosis on the prognosis of breast cancer.

\section{Materials and methods}

\section{Study population}

A total of 1,586 newly diagnosed breast cancer cases were recruited from Seoul National University Hospital and Asan Medical Center in Korea from 2004 to 2007 [19]. Before any adjuvant chemotherapy and/or surgery, baseline data were collected using questionnaires. Patients with a prehistory of cancer, multiple cancers at diagnosis, distant organ metastasis at diagnosis, in situ breast cancer and unobtainable of dietary assessment were excluded. Subjects with a total energy intake from 500 to $3,500 \mathrm{kcal} /$ day were included for the final analysis. In the final analysis, a total of 980 invasive ductal carcinoma cancer patients diagnosed with stage I - III who underwent curative resection were included.

The study was approved by the Committee on Human Research of Seoul National University Hospital (IRB No. H-0503-144-004). All participants provided informed consent before their participation in the study.

\section{Data collection}

The demographic characteristics of the participants were obtained by trained interviewers using a structured questionnaire. Information on demographic characteristics including age, education, reproductive and menstrual factors and lifestyle habits including smoking status, and alcohol consumption were collected.

A retrospective chart review was used to collect clinicopathological information including cancer stage, tumor size, lymph-node status, distant organ metastasis, estrogen receptor (ER) and progesterone receptor (PR) status, nuclear grade, surgical treatment and medical adjuvant therapy. Death was ascertained from Statistics Korea.

The food frequency questionnaire (FFQ) included 103 food items and detailed information on the FFQ has been described in a previous study [20]. During the inperson interviews, each participant was asked about their dietary habits for one year before the date of diagnosis. The frequency of servings was classified into nine 
categories: never or seldom, once a month, 2-3 times a month, one to two times a week, three to four times a week, five to six times a week, once a day, twice a day or three times or more every day. For food items with different seasonal availability, we requested that participants choose one category for how long they have eaten a particular food item from among four categories: 3, 6, 9 or 12 months. The portion size of each food item was classified as follows: small, medium or large. To help in understanding portion sizes, we provided pictures on serving sizes for food items on their corresponding pages. The reproducibility and validity of the FFQ were analyzed for 124 subjects in a previous study [20]. The FFQ was assessed twice at 1-year intervals for the reproducibility analysis. The correlation coefficients of the nutrients were $0.54,0.44$ and 0.43 for vitamin $B_{2}$ (unpublished data), vitamin $\mathrm{B}_{6}$ and folate, respectively. FFQs were compared with 12-day diet records (3 days during each of the four seasons) for the validity analysis. The correlation coefficients of the nutrients were ranged from 0.15 to 0.31 for vitamin $B_{2}$ (unpublished data), vitamin $B_{6}$ and folate [20].

\section{Statistical analysis}

Disease free survival (DFS) was defined as the time from the date of surgery to the date of the first locoregional recurrence, first distant metastasis, $2^{\text {nd }}$ primary cancer or death from any cause. Patients known to be alive with no evidence of disease were censored at the last follow-up date.

Cox's proportional hazard regression models were used to estimate the hazard ratio (HR) and 95\% confidence interval (95\% CI). Multivariate Model 1 included age, TNM stage, hormone status and nuclear grade while Model 2 included age, education, recruitment sites, TNM stage, hormone status and nuclear grade. In addition, onecarbon metabolism related nutrients were adjusted for total calories in both Model 1 and Model 2. The adjusted variables in Model 1 were known factors of breast cancer prognosis and the variables added to Model 2 were known factors related to the intake of nutrients. Other covariates including tumor size and lymph node status were considered but not included in the final model, since the TNM stage was adjustment variable in the final model.

We performed analyses with vitamin $B_{2}$, vitamin $B_{6}$ and folate as continuous variables and as categorical variables in quartiles. To further assess the combined effects of the intake of one-carbon metabolism related nutrients including vitamin $B_{2}$, vitamin $B_{6}$ and folate on breast cancer survival, each vitamin was coded as 0 or 1 by median, and calculated using the sum of the numbers. The combined score was categorized into three groups which were low (score, 0 ), medium (score, 1-2) and high (score, 3 ).

Wald $P$ values for trends were computed by treating categorical variables as ordinal variables. $P$ for interaction was analyzed by multiplying two variables.
Additionally, stratified analyses were done according to age ( $\leq 39,40-49,50-59$, and $\geq 60)$, menopausal status, BMI group $\left(<25 \mathrm{~kg} / \mathrm{m}^{2}\right.$ and $\left.\geq 25 \mathrm{~kg} / \mathrm{m}^{2}\right)$, alcohol consumption ( $<1 /$ month, $1+/$ month), TNM stage (I-II and III), lymph-node status (negative and positive), hormone status (ER + and/or $\mathrm{PR}+$ and $\mathrm{ER}-/ \mathrm{PR}-)$ and nuclear grade (I-II and III).

All statistical analyses were done using SAS statistical software version 9.2 (SAS Institute, Cary, NC).

\section{Results}

The median follow-up time was 5.3 years (range, 0.27.0 years). There were 141 DFS events including 77 deaths from any cause among all 980 patients. Table 1 summarizes the association between demographic and clinicopathological factors and progression in breast cancer patients. In this study, breast cancer patients who were estrogen receptor negative $(\mathrm{ER}-)$ and progesterone receptor negative (PR-) were $39.2 \%$ and $44.2 \%$, respectively. Among demographic factors, patients with an education higher than the college level were associated with progression of breast cancer compared to the patients with an education lower than middle school. Among clinical factors, TNM stage, tumor size, lymph node status and hormone status were significant prognostic factors for breast cancer $(P<0.05)$.

Table 2 presents the association between one-carbon metabolism related nutrients intake and disease progression in breast cancer patients. The mean intakes \pm SD of vitamin $\mathrm{B}_{2}, \mathrm{~B}_{6}$ and folate were $1.0 \pm 0.4 \mathrm{mg}, 1.5 \pm 0.5 \mathrm{mg}$ and $213.8 \pm 99.3 \mathrm{mg}$ respectively. Patients with a high (range, > median) intake of vitamin $\mathrm{B}_{2}, \mathrm{~B}_{6}$, and folate had an increased HR for the recurrence compared to the patients with a low (range, < median) intake; however, the association was not statistically significant. When examining the association between the combined effects of vitamin $B_{2}, B_{6}$ and folate intake on the progression of breast cancer, the HR was 1.46 (95\% CI, 0.87-2.43) for the high combined score group (range, 3) compared to the low combined score group (range, 0 ).

Table 3 presentes the association between the median of one-carbon metabolism related nutrients intake and disease progression in breast cancer patients stratified by clinicopathological characteristics. No differential association was found between the intake levels of vitamin $B_{2}$, $\mathrm{B}_{6}$, and folate and disease progression stratified by TNM stage, lymph-node status, or nuclear grade. However, in ER-/PR - breast cancers, a high intake of vitamin $B_{2}$ and folate statistically elevated the HR of breast cancer progression compared to a low intake $(\mathrm{HR}=2.28 ; 95 \% \mathrm{CI}$, 1.20-4.35, $\mathrm{HR}=1.84 ; 95 \% \mathrm{CI}, 1.02-3.32$, respectively). Low versus high (reference $=$ low) intake of vitamin $\mathrm{B}_{6}$ showed an increased HR for breast cancer progression; however, 
Table 1 Hazard ratios for disease progression in breast cancer patients

\begin{tabular}{|c|c|c|c|c|}
\hline & All $(\mathrm{N}=980)$ & Events $(N=141)$ & Model $1^{a}$ & Model $2^{b}$ \\
\hline Age (mean(SD)) & $48(9.8)$ & $49(11.7)$ & $1.02(1.00-1.04)$ & $1.01(0.99-1.03)$ \\
\hline$\leq 39$ & $191(19.5)$ & $30(21.3)$ & 1.00 & 1.00 \\
\hline $40-49$ & $422(43.0)$ & $50(35.5)$ & $0.86(0.54-1.36)$ & $0.76(0.48-1.22)$ \\
\hline $50-59$ & $241(24.6)$ & $34(24.1)$ & $1.02(0.62-1.70)$ & $0.83(0.48-1.42)$ \\
\hline$\geq 60$ & $126(12.9)$ & $27(19.1)$ & $1.66(0.97-2.82)$ & $1.21(0.67-2.18)$ \\
\hline \multicolumn{5}{|l|}{ Menopausal status } \\
\hline Pre & $610(63.0)$ & $74(53.6)$ & 1.00 & 1.00 \\
\hline Post & $359(37.0)$ & $64(46.4)$ & $1.50(0.93-2.42)$ & $1.38(0.85-2.25)$ \\
\hline $\mathrm{BMI}, \mathrm{kg} / \mathrm{m}^{2}(\operatorname{mean}(\mathrm{SD}))$ & $23(2.9)$ & $23(3.2)$ & $0.98(0.92-1.04)$ & $0.97(0.91-1.03)$ \\
\hline$<25$ & $753(77.6)$ & $107(77.0)$ & 1.00 & 1.00 \\
\hline$\geq 25$ & $217(22.4)$ & $32(23.0)$ & $0.85(0.56-1.28)$ & $0.79(0.52-1.20)$ \\
\hline \multicolumn{5}{|l|}{ Education } \\
\hline Middle school & $224(22.9)$ & $46(32.6)$ & 1.00 & 1.00 \\
\hline High school & $402(41.2)$ & $56(39.7)$ & $0.68(0.45-1.05)$ & $0.69(0.45-1.05)$ \\
\hline College & $351(35.9)$ & $39(27.7)$ & $0.58(0.36-0.94)$ & $0.58(0.36-0.93)$ \\
\hline \multicolumn{5}{|l|}{ Alcohol drinking } \\
\hline$<1 /$ month & $559(57.5)$ & $85(60.7)$ & 1.00 & 1.00 \\
\hline 1-3/month & $354(36.4)$ & $46(32.9)$ & $0.83(0.57-1.21)$ & $0.83(0.57-1.22)$ \\
\hline 1+/week & $59(6.1)$ & $9(6.4)$ & $1.12(0.56-2.25)$ & $1.09(0.54-2.19)$ \\
\hline \multicolumn{5}{|l|}{ Recruited sites } \\
\hline SNU & $511(52.1)$ & $73(51.8)$ & 1.00 & 1.00 \\
\hline AMC & $469(47.9)$ & $68(48.2)$ & $0.92(0.65-1.30)$ & $0.89(0.63-1.26)$ \\
\hline \multicolumn{5}{|l|}{ TNM stage } \\
\hline 1 & $400(40.8)$ & $25(17.7)$ & 1.00 & 1.00 \\
\hline$\|$ & $416(42.5)$ & $72(51.1)$ & $2.78(1.74-4.44)$ & $2.71(1.69-4.35)$ \\
\hline III & $164(16.7)$ & $44(31.2)$ & $4.27(2.57-7.11)$ & $4.17(2.50-6.96)$ \\
\hline \multicolumn{5}{|l|}{ Tumor size } \\
\hline$<2 \mathrm{~cm}$ & $526(54.9)$ & $42(29.8)$ & 1.00 & 1.00 \\
\hline$\geq 2 \mathrm{~cm}$ & $431(44.9)$ & $99(70.2)$ & $2.57(1.74-3.79)$ & $2.51(1.70-3.72)$ \\
\hline Tx & $2(0.2)$ & & & \\
\hline \multicolumn{5}{|l|}{ Lymph node status } \\
\hline Negative & $577(58.9)$ & $60(42.6)$ & 1.00 & 1.00 \\
\hline Positive & $390(39.8)$ & $78(55.3)$ & $1.47(1.03-2.11)$ & $1.46(1.02-2.09)$ \\
\hline Nx & $13(1.3)$ & $3(2.1)$ & & \\
\hline \multicolumn{5}{|l|}{ Hormone status } \\
\hline $\mathrm{ER}+$ and/or PR+ & $698(72.6)$ & $74(53.6)$ & 1.00 & 1.00 \\
\hline ER-/PR- & $264(27.4)$ & $64(46.4)$ & $2.06(1.41-3.01)$ & $2.06(1.40-3.02)$ \\
\hline \multicolumn{5}{|l|}{ Nuclear grade } \\
\hline$|-| \mid$ & $525(55.2)$ & $57(41.0)$ & 1.00 & 1.00 \\
\hline III & $426(44.8)$ & $82(59.0)$ & $1.15(0.78-1.69)$ & $1.12(0.75-1.65)$ \\
\hline
\end{tabular}

Abbreviation: AMC, Asan Medical Center; ER, estrogen receptor; PR, progesterone receptor; SNU, Seoul National University.

Data are presented as frequency (percentage), except for age and BMI in continuous variable, which are expressed as mean (SD).

a Adjusted for age, TNM stage and hormone status and nuclear grade.

${ }^{\mathrm{b}}$ Adjusted for age, education, recruited site, TNM stage, hormone status and nuclear grade. 
Table 2 Association between one-carbon metabolism related nutrients intake and disease progression in breast cancer patients

\begin{tabular}{|c|c|c|c|c|}
\hline & All $(\mathrm{N}=980)$ & Events $(\mathrm{N}=141)$ & Model $1^{a}$ & Model $2^{b}$ \\
\hline \multicolumn{5}{|l|}{ Vitamin $B_{2}$ intake, $\mathrm{mg}$} \\
\hline Continuous (mean(SD)) & $1.0(0.4)$ & $1.0(0.4)$ & $1.21(0.67-2.18)$ & $1.29(0.71-2.33)$ \\
\hline $1^{\text {st }}$ quartile $(0.1-0.6)$ & $192(19.6)$ & $29(20.6)$ & 1.00 & 1.00 \\
\hline $2^{\text {nd }}$ quartile (0.7-0.8) & $226(23.1)$ & $26(18.4)$ & $0.94(0.54-1.61)$ & $0.99(0.58-1.73)$ \\
\hline $3^{\text {rd }}$ quartile (0.9-1.1) & $295(30.1)$ & $44(31.2)$ & $1.20(0.71-2.02)$ & $1.28(0.75-2.18)$ \\
\hline $4^{\text {th }}$ quartile $(1.2-3.4)$ & $267(27.2)$ & $42(29.8)$ & $1.40(0.76-2.61)$ & $1.58(0.84-2.98)$ \\
\hline$P_{\text {trend }}$ & & & 0.21 & 0.12 \\
\hline \multicolumn{5}{|l|}{ Vitamin $\mathrm{B}_{6}$ intake, mg } \\
\hline Continuous (mean(SD)) & $1.5(0.5)$ & $1.5(0.6)$ & $1.41(0.90-2.20)$ & $1.38(0.88-2.17)$ \\
\hline $1^{\text {st }}$ quartile $(0.1-1.0)$ & $174(17.8)$ & $26(18.4)$ & 1.00 & 1.00 \\
\hline $2^{\text {nd }}$ quartile (1.1-1.3) & $262(26.7)$ & $39(27.7)$ & $1.27(0.75-2.16)$ & $1.28(0.75-2.18)$ \\
\hline $3^{\text {rd }}$ quartile $(1.4-1.7)$ & $238(24.3)$ & 27 (19.2) & $0.97(0.72-1.80)$ & $0.98(0.53-1.83)$ \\
\hline $4^{\text {th }}$ quartile (1.8-4.8) & $306(31.2)$ & $49(34.8)$ & $1.61(0.82-3.16)$ & $1.65(0.84-3.24)$ \\
\hline$P_{\text {trend }}$ & & & 0.29 & 0.27 \\
\hline \multicolumn{5}{|l|}{ Folate intake, mg } \\
\hline Continuous (mean(SD)) & $213.8(99.3)$ & $212.9(98.3)$ & $1.00(0.99-1.00)$ & $1.00(0.99-1.00)$ \\
\hline $1^{\text {st }}$ quartile $(9-147)$ & $240(24.5)$ & $37(26.2)$ & 1.00 & 1.00 \\
\hline $2^{\text {nd }}$ quartile (148-199) & $248(25.3)$ & $32(22.7)$ & $0.82(0.51-1.33)$ & $0.82(0.51-1.34)$ \\
\hline $3^{\text {rd }}$ quartile (200-256) & $247(25.2)$ & $33(23.4)$ & $0.96(0.58-1.60)$ & $0.97(0.58-1.63)$ \\
\hline $4^{\text {th }}$ quartile (257-970) & $245(25.0)$ & $39(27.7)$ & $1.18(0.68-2.03)$ & $1.20(0.69-2.07)$ \\
\hline$P_{\text {trend }}$ & & & 0.50 & 0.46 \\
\hline \multicolumn{5}{|l|}{ Combined score } \\
\hline Low (0) & $302(30.8)$ & $44(31.2)$ & 1.00 & 1.00 \\
\hline Medium (1-2) & $289(29.5)$ & $35(24.8)$ & $0.92(0.58-1.47)$ & $0.93(0.58-1.50)$ \\
\hline High (3) & 389 (39.7) & $62(44.0)$ & $1.40(0.84-2.33)$ & $1.46(0.87-2.43)$ \\
\hline$P_{\text {trend }}$ & & & 0.20 & 0.15 \\
\hline
\end{tabular}

Data are presented as frequency (percentage), except for continuous variable, which are expressed as mean (SD).

${ }^{a}$ Adjusted for age, TNM stage, hormone status, nuclear grade and total calorie.

${ }^{\mathrm{b}}$ Adjusted for age, education, recruited site, TNM stage, hormone status, nuclear grade and total calorie.

the association was not significant $\left(\mathrm{P}_{\text {interaction }}=0.04, \mathrm{HR}=\right.$ 1.86; 95\% CI, 0.97-3.56).

Furthermore, we evaluated the association between the combined scores of one-carbon metabolism related nutrients intake and disease progression in breast cancer patients stratified by hormone status (Table 4). The positive association between ER/PR status was profound when the nutrient intakes were categorized by combined score $\left(P_{\text {interaction }}=0.018\right)$. In ER-/PR- cancers, the high combined score (range, 3 ) group was associated with a significantly poor DFS compared to those belonging to the low score (range, 0$)$ group ( $\mathrm{HR}=3.84 ; 95 \% \mathrm{CI}, 1.70-8.71$ ).

\section{Discussion}

There was no association between one-carbon metabolism related nutrients and disease free survival of breast cancer overall, while some effects were observed when stratifying by breast cancer subtypes. To the best of our knowledge, this study is the first to systematically investigate the association between the combined effects of prediagnostic intake of nutrients related to the onecarbon metabolism pathway and the clinicopathological characteristics of breast cancer.

In our study, the range for the intake of vitamin $B_{2}, B_{6}$ and folate were $0.1-3.4 \mathrm{mg}, 0.1-4.8 \mathrm{mg}$ and $9-970 \mathrm{mg}$, respectively. These levels of vitamin $\mathrm{B}_{6}$ and folate were less than the tolerable upper intake level of Dietary Reference Intakes for Koreans (KDRIs). The tolerable upper intake of vitamin $\mathrm{B}_{2}$ level was not determinable by the KDRIs. In the KDRIs, the tolerable upper intake level of vitamin $B_{6}$ and folate were $100 \mathrm{mg}$ and $1000 \mathrm{mg}$. The levels of dietary intake of vitamin $B_{2}, B_{6}$, and folate in breast cancer patients were hardly reported. Even though there were many previous studies on the 
Table 3 Association between median of one-carbon metabolism related nutrients and disease progression in breast cancer patients stratified by clinicopathological characteristics

\begin{tabular}{|c|c|c|c|c|c|c|}
\hline & & \multicolumn{2}{|c|}{ Below median } & \multicolumn{2}{|c|}{ Above median } & \multirow[b]{2}{*}{$\operatorname{HR}(95 \% \mathrm{Cl})^{\mathrm{a}}$} \\
\hline & & No. of total & No. of events & No. of total & No. of events & \\
\hline & TNM stage & & & & & \\
\hline \multirow{2}{*}{ Vitamin $B_{2}, \mathrm{mg}$} & $|-| \mid$ & 350 & 39 & 466 & 58 & $1.40(0.85-2.30)$ \\
\hline & III & 68 & 16 & 96 & 28 & $1.13(0.52-2.43)$ \\
\hline \multirow{2}{*}{ Vitamin $\mathrm{B}_{6}, \mathrm{mg}$} & $|-| \mid$ & 362 & 46 & 454 & 51 & $1.02(0.61-1.73)$ \\
\hline & III & 74 & 19 & 90 & 25 & $1.05(0.49-2.27)$ \\
\hline \multirow[t]{3}{*}{ Folate, mg } & $|-| \mid$ & 397 & 48 & 419 & 49 & $1.10(0.69-1.75)$ \\
\hline & ॥ा & 91 & 21 & 73 & 23 & $1.52(0.77-3.01)$ \\
\hline & Lymph-node status & & & & & \\
\hline \multirow[t]{2}{*}{ Vitamin $B_{2}, \mathrm{mg}$} & Negative & 242 & 25 & 335 & 35 & $1.28(0.67-2.42)$ \\
\hline & Positive & 172 & 29 & 218 & 49 & $1.40(0.81-2.44)$ \\
\hline \multirow[t]{2}{*}{ Vitamin $\mathrm{B}_{6}, \mathrm{mg}$} & Negative & 251 & 28 & 326 & 32 & $1.22(0.63-2.34)$ \\
\hline & Positive & 181 & 36 & 209 & 42 & $0.88(0.49-1.56)$ \\
\hline \multirow[t]{3}{*}{ Folate, mg } & Negative & 284 & 30 & 293 & 30 & $1.23(0.68-2.24)$ \\
\hline & Positive & 199 & 38 & 191 & 40 & $1.12(0.67-1.87)$ \\
\hline & Hormone status & & & & & \\
\hline \multirow[t]{2}{*}{ Vitamin $B_{2}, \mathrm{mg}$} & $\mathrm{ER}+$ and/or PR+ & 300 & 34 & 398 & 40 & $0.91(0.52-1.59)$ \\
\hline & ER-/PR- & 111 & 21 & 153 & 43 & $2.28(1.20-4.35)$ \\
\hline \multirow[t]{2}{*}{ Vitamin $\mathrm{B}_{6}, \mathrm{mg}$} & $\mathrm{ER}+$ and/or PR+ & 305 & 39 & 393 & 35 & $0.57(0.32-1.03)$ \\
\hline & ER-/PR- & 125 & 26 & 139 & 38 & $1.86(0.97-3.56)$ \\
\hline \multirow[t]{3}{*}{ Folate, mg } & $\mathrm{ER}+$ and/or PR+ & 333 & 39 & 365 & 35 & $0.82(0.49-1.40)$ \\
\hline & ER-/PR- & 148 & 30 & 116 & 34 & $1.84(1.02-3.32)$ \\
\hline & Nuclear grade & & & & & \\
\hline \multirow[t]{2}{*}{ Vitamin $B_{2}, \mathrm{mg}$} & $|-| \mid$ & 223 & 23 & 302 & 34 & $1.22(0.64-2.34)$ \\
\hline & III & 185 & 32 & 241 & 50 & $1.43(0.82-2.49)$ \\
\hline \multirow[t]{2}{*}{ Vitamin $\mathrm{B}_{6}, \mathrm{mg}$} & $|-| \mid$ & 226 & 29 & 299 & 28 & $0.56(0.28-1.11)$ \\
\hline & III & 200 & 36 & 226 & 46 & $1.28(0.73-2.24)$ \\
\hline \multirow[t]{2}{*}{ Folate, mg } & $|-| \mid$ & 250 & 31 & 275 & 26 & $0.69(0.38-1.27)$ \\
\hline & III & 224 & 38 & 202 & 44 & $1.59(0.95-2.66)$ \\
\hline
\end{tabular}

Abbreviation: $\mathrm{ER}$, estrogen receptor; $\mathrm{PR}$, progesterone receptor.

a Adjusted for age, education, recruited site, TNM stage, hormone status, nuclear grade and total calorie.

association between vitamin $B_{2}, B_{6}$ and folate and breast cancer risk, they reported the tertiles or quartile levels in both the cases and the controls. Thus, it is hard to compare the nutrients intake level of patients' with other studies that used different designs.

In observational studies, the results for the relationship between micronutrient intakes and all-cause mortality were inconsistent among breast cancer patients [21]. Only one study investigated one-carbon metabolism related nutrients intake and all-cause of mortality in women with breast cancer, and showed null results for vitamin $B_{2}, B_{6}$ and folate [17]. Few studies have investigated the association between folate intake and breast cancer survival. McEligot et al. studied 516 postmenopausal women diagnosed with breast cancer for 6.6 years (median follow-up) and showed that women in the highest tertile for dietary folate intake had an HR of 0.34 (95\% CI, 0.180.67) regarding all-cause mortality [22]. In addition, in the Swedish mammography cohort, dietary folate intake was inversely associated with overall mortality $(\mathrm{HR}=0.79 ; 95 \%$ CI, 0.66-0.96) [16]. However, in the Iowa Women's Health Study, Sellers et al. reported that among 177 breast cancer patients, folate intake had no association with breast cancer prognosis [23]. Moreover, in the Nurses' Health Study, Holmes et al. provided additional support for no association of breast cancer prognosis with vitamin $B_{2}, B_{6}$ and folate [18]. In addition, Rossi et al. measured the folate levels in plasma from 1024 breast cancer patients in 
Table 4 Association between combined score of one-carbon metabolism related nutrients intake and disease progression in breast cancer patients stratified by selected characteristics

\begin{tabular}{|c|c|c|c|c|}
\hline & Combined score & No. of total & No. of events & $\mathrm{HR}(95 \% \mathrm{Cl})^{a}$ \\
\hline \multicolumn{5}{|l|}{ Hormone status $^{\mathrm{b}}$} \\
\hline \multirow[t]{4}{*}{$\mathrm{ER}+$ and/or PR+ } & Low (0) & 211 & 29 & 1.00 \\
\hline & Medium (1-2) & 202 & 16 & $0.54(0.29-1.02)$ \\
\hline & High (3) & 285 & 29 & $0.72(0.37-1.43)$ \\
\hline & $P_{\text {trend }}$ & & & 0.29 \\
\hline \multirow[t]{4}{*}{ ER-/PR- } & Low (0) & 87 & 15 & 1.00 \\
\hline & Medium (1-2) & 82 & 19 & $2.02(0.96-4.27)$ \\
\hline & High (3) & 95 & 30 & $3.84(1.70-8.71)$ \\
\hline & $P_{\text {trend }}$ & & & 0.001 \\
\hline
\end{tabular}

Abbreviation: ER, estrogen receptor; PR, progesterone receptor.

${ }^{\text {a }}$ Adjusted for age, education, recruited site, TNM stage, hormone status, nuclear grade and total calorie.

${ }^{\mathrm{b}} P$ for interaction $=0.018$.

Australia and reported that plasma folate was not significantly associated with breast cancer survival [24]. No other prior studies have reported the relationship between one-carbon metabolism related factors and their combined intake effects on the prognosis of breast cancer. The lack of consensus in the results of previous studies could be explained by the variation in study methodologies, micronutrient source, and total micronutrient level. Thus, it is difficult to determine how the micronutrient intake distribution reported in one study compares to other studies [25].

We observed that the combined intake effects of vita$\min B_{2}, B_{6}$, and folate were associated with breast cancer progression in patients depending on their ER/PR status. No previous studies examining the combined intake effects of one-carbon metabolism related nutrients intake and hormone specific breast cancer have been identified. In the Swedish Mammography Cohort (SMC), only folate intake, which is one of the one-carbon metabolism related nutrients studies, was assessed for association with breast cancer progression [20]. Although Harris et al. have reported that dietary folate intake has shown protective effects on breast cancer-specific mortality in ER-negative tumors, our results do not support this effect. It is difficult directly compare our study's results to theirs since the distribution of the hormone receptors in the study subjects was different (ER-negative breast cancer, less than 20\% in SMC; $39.2 \%$ in the present study). For breast cancer risk, few studies have evaluated the relationship between hormone status and folate intake. A higher folate intake was associated with a lower risk of ER-negative breast cancer in the Nurses' Health Study [26], and in the VITamins And Lifestyle (VITAL) cohort [27]. In SMC, a high folate intake was related to a decreased risk of ER+/PR- breast cancer [28]. Otherwise, few cohort studies have reported largely null results, with no findings for associations between folate intake and
ER+, ER-, PR + or PR- breast cancers [26,27,29,30]. From various laboratory studies, their results were inconsistent with our study, which examined whether DNA methylation of the ER CPG island may play a role in suppressing ER gene expression in ER-negative breast cancer cells [31,32]. A greater supply of methyl through a high intake of one-carbon metabolism related nutrients may induce the suppression of gene expression in patients with ER-/PR- breast cancers. In addition, a high intake of one-carbon metabolism related nutrients may have a stronger effect on ER-/PR- breast cancer progression than the other types of breast cancers since ER-/PRbreast cancers are less responsive to hormone therapies. Further studies are needed to elucidate the possible association between one-carbon metabolism related nutrients and the hormone receptors in breast cancer patients.

The results of our study were contrary to the hypothesis based on previous studies that a higher intake of B vitamins would have a protective effect on breast cancer survival in population based studies. One prospective cohort study suggested the association of major energy sources with breast cancer survival may be U-shaped rather than linear [33]. As far as this idea, the association has not yet been proven; however, a midrange intake of vitamins is associated with the most favorable outcomes, and extremes are associated with less favorable outcomes.

This study has some limitations. First, there were likely errors in our estimate of dietary habits. Patients were asked about their dietary intake for the year preceding the diagnosis using the FFQ. Due to this, measurement errors likely occurred because of poor recall despite the validity and reproducibility evidence of the questionnaire. The FFQ correlations were lower than that reported in western countries which were between 0.50.7 [34]. In Asia, the median of the correlation coefficients for the FFQ has ranged from 0.3-0.5 in Japan $[35,36]$ and Korea [37,38], and a lower FFQ correlation 
may have been caused by the dining etiquette and cultural foods of Korea [20]. Though the correlation coefficients were low, to date, FFQ is the only method in which long-term usual dietary intake of an individual can be easily obtained with a single measurement [39]. Second, intake of supplements was not available for the calculations. However, the intake of supplements use can improve the dietary quality for certain micronutrients [25]. Lastly, we could not evaluate the association between one-carbon metabolism related nutrients and breast cancer specific mortality because the data for the cause of death were not available. Thus, the results must be interpreted cautiously and need to be confirmed by a study that investigates the association of one-carbon metabolism related nutrients with breast cancer specific survival.

Nevertheless, our study has strengths. It is the first study to evaluate the association between the combined intake effects of vitamin $B_{2}, B_{6}$ and folate and hormone specific breast cancer survival.

\section{Conclusion}

In summary, one-carbon metabolism related nutrients are associated with disease free survival depending on the ER/PR status among breast cancer patients. However, because of the small population in these subgroup analyses, these results should be interpreted with caution. Future studies examining the pathways of onecarbon metabolism related nutrients in certain breast cancer types must account for the direct or indirect roles of these nutrients.

\section{Abbreviations}

AMC: Asan Medical Center; Cl: Confidence interval; DFS: Disease free survival; DRs: Diet records; ER: Estrogen receptor; FFQ: Food frequency questionnaire HR: Hazard ratio; KDRIs: Dietary Reference Intakes for Koreans; PR: Progesterone receptor; SD: Standard deviation; SNU: Seoul National University; SMC: Swedish Mammography Cohort.

\section{Competing interests}

The authors declare that they have no competing interests.

\section{Author's contributions}

DK, DYN, and SHA were Pls for each of the participating cooperative groups of the Seoul Breast Cancer Study (SeBCS). YL, SAL, JYC, SKP, KYY and DK were involved in conception and design of the study and participated in the discussion and interpretation of the results. YL carried out data analysis and writing of the manuscript. MS, HS and SJ contributed to statistical analyses and helped to draft the manuscript. All authors have read and approved the final manuscript.

\section{Acknowledgement}

Grant support: This work was supported by the Basic Science Research Program through the National Research Foundation of Korea funded by the Ministry of Education, Science and Technology [2011-0027212].

\section{Author details}

'Department of Biomedical Sciences, Seoul National University, Seoul, Republic of Korea. ${ }^{2}$ Department of Preventive Medicine, Kangwon National University School of Medicine, Kangwon, Republic of Korea. ${ }^{3}$ Department of Molecular Medicine and Biopharmaceutical Sciences, Graduate School of
Convergence Science and Technology and College of Medicine or College of Pharmacy, Seoul, Republic of Korea. ${ }^{4}$ Department of Preventive Medicine, Seoul National University, Seoul, Republic of Korea. ${ }^{5}$ Department of Surgery, Seoul National University College of Medicine, Seoul, Republic of Korea.

${ }^{6}$ Department of Surgery, University of Ulsan College of Medicine and Asan Medical Center, Ulsan, Republic of Korea. 'Department of Preventive Medicine, Seoul National University College of Medicine, 103 Yongon (Daehangno), Jongno-gu, Seoul, Republic of Korea.

Received: 6 January 2012 Accepted: 11 August 2012

Published: 28 August 2012

\section{References}

1. Cancer Facts \& Figures 2010 in the Republic of Korea; http://www.cancer.go. $\mathrm{kr} / \mathrm{cms} /$ data/edudata/_icsFiles/afieldfile/2010/07/21/ cancer_fact_figures_2010_english.pdf.

2. Cianfrocca $\mathrm{M}$, Goldstein LJ: Prognostic and predictive factors in early-stage breast cancer. Oncologist 2004, 9:606-616.

3. Osborne CK: Steroid hormone receptors in breast cancer management. Breast Cancer Res Treat 1998, 51:227-238.

4. Page DL, Jensen RA, Simpson JF: Routinely available indicators of prognosis in breast cancer. Breast Cancer Res Treat 1998, 51:195-208.

5. Esteller M: Epigenetics in cancer. N Engl J Med 2008, 358:1 148-1159.

6. Christman JK, Sheikhnejad G, Dizik M, Abileah S, Wainfan E: Reversibility of changes in nucleic acid methylation and gene expression induced in rat liver by severe dietary methyl deficiency. Carcinogenesis 1993, 14:551-557.

7. Choi SW, Mason JB: Folate and carcinogenesis: an integrated scheme. J Nutr 2000, 130:129-132.

8. Stern LL, Bagley PJ, Rosenberg IH, Selhub J: Conversion of 5 -formyltetrahydrofolic acid to 5 -methyltetrahydrofolic acid is unimpaired in folate-adequate persons homozygous for the C677T mutation in the methylenetetrahydrofolate reductase gene. J Nutr 2000, 130:2238-2242.

9. Friso S, Choi SW: Gene-nutrient interactions in one-carbon metabolism. Curr Drug Metab 2005, 6:37-46.

10. Mason JB: Biomarkers of nutrient exposure and status in one-carbon (methyl) metabolism. J Nutr 2003, 133(Suppl 3):941S-947S.

11. Stolzenberg-Solomon RZ, Albanes D, Nieto FJ, Hartman TJ, Tangrea JA, Rautalahti M, Sehlub J, Virtamo J, Taylor PR: Pancreatic cancer risk and nutrition-related methyl-group availability indicators in male smokers. J Natl Cancer Inst 1999, 91:535-541.

12. Larsson SC, Giovannucci E, Wolk A: Folate intake, MTHFR polymorphisms, and risk of esophageal, gastric, and pancreatic cancer: a meta-analysis. Gastroenterology 2006, 131:1271-1283.

13. Kim Yl: Folate and colorectal cancer: an evidence-based critical review. Mol Nutr Food Res 2007, 51:267-292.

14. Gibson TM, Weinstein SJ, Mayne ST, Pfeiffer RM, Selhub J, Taylor PR, Virtamo J, Albanes D, Stolzenberg-Solomon R: A prospective study of one-carbon metabolism biomarkers and risk of renal cell carcinoma. Cancer Causes Control 2010, 21:1061-1069.

15. $\mathrm{Xu} X, \mathrm{Chen} \mathrm{J:} \mathrm{One-carbon} \mathrm{metabolism} \mathrm{and} \mathrm{breast} \mathrm{cancer:} \mathrm{an}$ epidemiological perspective. J Genet Genomics 2009, 36:203-214.

16. Harris $H R$, Bergkvist $L$, Wolk $A$ : Folate intake and breast cancer mortality in a cohort of Swedish women. Breast Cancer Res Treat 2011, 132:243-250.

17. Xu X, Gammon MD, Wetmur JG, Bradshaw PT, Teitelbaum SL, Neugut Al Santella RM, Chen J: B-vitamin intake, one-carbon metabolism, and survival in a population-based study of women with breast cancer. Cancer Epidemiol Biomarkers Prev 2008, 17:2109-2116.

18. Holmes MD, Stampfer MJ, Colditz GA, Rosner B, Hunter DJ, Willett WC: Dietary factors and the survival of women with breast carcinoma. Cancer 1999, 86:826-835.

19. Han S, Lee KM, Choi JY, Park SK, Lee JY, Lee JE, Noh DY, Ahn SH, Han W, Kim DH, et al: CASP8 polymorphisms, estrogen and progesterone receptor status, and breast cancer risk. Breast Cancer Res Treat 2008, 110:387-393.

20. Ahn Y, Kwon E, Shim JE, Park MK, Joo Y, Kimm K, Park C, Kim DH: Validation and reproducibility of food frequency questionnaire for Korean genome epidemiologic study. Eur J Clin Nutr 2007, 61:1435-1441.

21. Rock CL, Demark-Wahnefried W: Nutrition and survival after the diagnosis of breast cancer: a review of the evidence. J Clin Oncol 2002, 20:3302-3316. 
22. McEligot AJ, Largent J, Ziogas A, Peel D, Anton-Culver H: Dietary fat, fiber, vegetable, and micronutrients are associated with overall survival in postmenopausal women diagnosed with breast cancer. Nutr Cancer 2006, 55:132-140.

23. Sellers TA, Alberts SR, Vierkant RA, Grabrick DM, Cerhan JR, Vachon CM, Olson JE, Kushi LH, Potter JD: High-folate diets and breast cancer survival in a prospective cohort study. Nutr Cancer 2002, 44:139-144.

24. Rossi E, Hung J, Beilby JP, Knuiman MW, Divitini ML, Bartholomew H: Folate levels and cancer morbidity and mortality: prospective cohort study from Busselton, Western Australia. Ann Epidemiol 2006, 16:206-212.

25. Saquib J, Rock CL, Natarajan L, Saquib N, Newman VA, Patterson RE, Thomson CA, Al-Delaimy WK, Pierce JP: Dietary intake, supplement use, and survival among women diagnosed with early-stage breast cancer. Nutr Cancer 2011, 63:327-333.

26. Zhang SM, Hankinson SE, Hunter DJ, Giovannucci EL, Colditz GA, Willett WC Folate intake and risk of breast cancer characterized by hormone receptor status. Cancer Epidemiol Biomarkers Prev 2005, 14:2004-2008.

27. Maruti SS, Ulrich CM, White E: Folate and one-carbon metabolism nutrients from supplements and diet in relation to breast cancer risk. Am J Clin Nutr 2009, 89:624-633.

28. Larsson SC, Bergkvist L, Wolk A: Folate intake and risk of breast cancer by estrogen and progesterone receptor status in a Swedish cohort. Cancer Epidemiol Biomarkers Prev 2008, 17:3444-3449.

29. Cho E, Holmes M, Hankinson SE, Willett WC: Nutrients involved in one-carbon metabolism and risk of breast cancer among premenopausal women. Cancer Epidemiol Biomarkers Prev 2007, $16: 2787-2790$

30. Sellers TA, Vierkant RA, Cerhan JR, Gapstur SM, Vachon CM, Olson JE, Pankratz VS, Kushi LH, Folsom AR: Interaction of dietary folate intake, alcohol, and risk of hormone receptor-defined breast cancer in a prospective study of postmenopausal women. Cancer Epidemiol Biomarkers Prev 2002, 11:1104-1107.

31. Lapidus RG, Nass SJ, Butash KA, Parl FF, Weitzman SA, Graff JG, Herman JG, Davidson NE: Mapping of ER gene CpG island methylation-specific polymerase chain reaction. Cancer Res 1998, 58:2515-2519.

32. Ferguson AT, Lapidus RG, Baylin SB, Davidson NE: Demethylation of the estrogen receptor gene in estrogen receptor-negative breast cancer cells can reactivate estrogen receptor gene expression. Cancer Res 1995 55:2279-2283.

33. Goodwin PJ, Ennis M, Pritchard KI, Koo J, Trudeau ME, Hood N: Diet and breast cancer: evidence that extremes in diet are associated with poor survival. J Clin Oncol 2003, 21:2500-2507.

34. Willett $\mathrm{W}$, Lenart $\mathrm{E}$ : Reprocucibility and validity of food-frequency questionairs. In Nutritional Epidemiology. 2nd edition. Edited by Willett W. New York: Oxford University Press; 1998:101-147.

35. Date C, Fukui M, Yamamoto A, Wakai K, Ozeki A, Motohashi Y, Adachi C, Okamoto N, Kurosawa M, Tokudome Y, et al: Reproducibility and validity of a self-administered food frequency questionnaire used in the JACC study. J Epidemiol 2005, 15(Suppl 1):S9-S23.

36. Tsugane S, Kobayashi M, Sasaki S, Jphc: Validity of the self-administered food frequency questionnaire used in the 5-year follow-up survey of the JPHC Study Cohort I: comparison with dietary records for main nutrients. J Epidemiol 2003, 13:S51-S56

37. Shim JS, Oh KW, Suh I, Kim MY, Sohn CY, Lee EJ, Nam CM: A study on validity of a semi-quantitative food frequency questionnaire for Korean adults. Korean J Community Nutrition 2002, 7:484-494.

38. Lee HJ, Park SJ, Kim JH, Kim Cl, Chang KJ, Yim KS, Kim KW, Choi HM: Development and validation of a computerized semi-quantitative food frequency questionnaire program for evaluating the nutritional status of the Korean elderly. Korean J Community Nutrition 2002, 7:277-285.

39. Willett W: Food-frequency questionnair. In Nutritional Epidemiology. 2nd edition. Edited by Willett W. New York: Oxford University Press; 1998:74-100.

doi:10.1186/1475-2891-11-59

Cite this article as: Lee et al:: Prognosis of breast cancer is associated with one-carbon metabolism related nutrients among Korean women Nutrition Journal 2012 11:59

\section{Submit your next manuscript to BioMed Central and take full advantage of:}

- Convenient online submission

- Thorough peer review

- No space constraints or color figure charges

- Immediate publication on acceptance

- Inclusion in PubMed, CAS, Scopus and Google Scholar

- Research which is freely available for redistribution

Submit your manuscript at www.biomedcentral.com/submit
C Biomed Central 